\title{
Is Exploitation Competition Involved in a Multitrophic Strategy for the Biocontrol of Fusarium Head Blight?
}

\author{
Sabrina Sarrocco, ${ }^{1, \dagger}$ Fabio Valenti, ${ }^{1}$ Sara Manfredini, ${ }^{1}$ Pilar Esteban, ${ }^{1}$ Rodolfo Bernardi, ${ }^{1}$ Grazia Puntoni, ${ }^{1}$ \\ Riccardo Baroncelli, ${ }^{2}$ Miriam Haidukowski, ${ }^{3}$ Antonio Moretti, ${ }^{3}$ and Giovanni Vannacci ${ }^{1}$
}

${ }^{1}$ Plant Pathology \& Mycology Lab, Dipartimento di Scienze Agrarie, Alimentari e Agro-Ambientali, Università degli Studi di Pisa Via del Borghetto 80, 56124 Pisa, Italy; ${ }^{2}$ Instituto Hispano-Luso de Investigaciones Agrarias, University of Salamanca, Calle del Duero, $12 ; 37185$ Villamayor (Salamanca), Spain; and ${ }^{3}$ ISPA-CNR, Via Amendola, 122/O, 70126 Bari, Italy.

Accepted for publication 21 September 2018

\begin{abstract}
Trichoderma gamsii T6085 was used in combination with a Fusarium oxysporum isolate (7121) in order to evaluate, in a multitrophic approach, their competitive ability against $F$. graminearum, one of the main causal agents of Fusarium head blight (FHB) on wheat. The two antagonists and the pathogen were coinoculated on two different natural substrates, wheat and rice kernels. Both T6085 and 7121, alone and coinoculated, significantly reduced the substrate colonization and mycotoxin production by the pathogen. The two antagonists did not affect each other. Using a metabolic approach (Biolog), we investigated whether exploitation competition could explain this antagonistic activity. The aim was to define whether the three fungi coexist or if one isolate nutritionally

dominates another. Results obtained from Biolog suggest that no exploitative competition occurs between the antagonists and the pathogen during the colonization of the natural substrates. Interference competition was then preliminarily evaluated to justify the reduction in the pathogen's growth and to better explain mechanisms. A significant reduction of $F$. graminearum growth was observed when the pathogen grew in the cultural filtrates of $T$. gamsii T6085, both alone and cocultured with F. oxysporum 7121, thus suggesting the involvement of secondary metabolites. As far as we know, this is the first time that an ecological study has been performed to explain how and which kind of competition could be involved in a multitrophic biocontrol of FHB.
\end{abstract}

Fusarium head blight (FHB) causes significant yield losses worldwide in crops such as wheat, maize, rice, and minor cereals (Parry et al. 1995; Xu and Nicholson 2009). Many different Fusarium spp. contribute to the disease, but Fusarium graminearum is one of the main causal agents (Parry et al. 1995). Infections of wheat by $F$. graminearum, as well as by other Fusarium spp., do not only reduce grain size, weight, germination rate, protein content, and baking quality of the flour but also the feed and food safety, due to the contamination of the grains with mycotoxins (Pieters et al. 2002). Strategies for controlling the disease and preventing mycotoxin accumulation such as fungicides, host resistance, or agronomical approaches do not fully reduce the impact of FHB, and new and sustainable strategies are greatly needed.

At the beginning of the 20th century, competitive interaction within coexisting populations was suggested as a mechanism to limit plant disease and to reduce pathogen populations (Kinkel et al. 1995). Two competition strategies are generally applied to fungal communities: exploitation competition and interference competition (Fokkema 1971; Hartley 1921; Wilson and Lindow 1994). Exploitation is the direct competition for resources by rapid scavenging from a common pool, whereas interference competition (or indirect competition) involves habitat monopolization by antagonistic combat (Keddy 2001). These definitions have now been adapted to biological control: exploitation competition is used for resources (oxygen, carbon, nitrogen, and other essential resources), whereas interference competition is used for space via antibiosis, where a biological control agent inhibits the pathogen through the effects of toxic secondary metabolites or other means of combat (Jensen et al. 2017).

${ }^{\dagger}$ Corresponding author: S. Sarrocco; E-mail: sabrina.sarrocco@unipi.it

The author(s) declare no conflict of interest.

(c) 2019 The American Phytopathological Society
During the disease cycle, $F$. graminearum uses cultural debris to overwinter between two consecutive cultural cycles, while flowering is the most susceptible wheat growth stage for spike infection (Champeil et al. 2004; Parry et al. 1995). Because this pathogen is generally considered a poor competitor over time compared with other organisms that colonize crop residues (Pereyra and DillMacky 2008), competition could thus be a valid strategy to control the production of the primary inoculum (Leplat et al. 2013). If biocontrol agents are inoculated on cultural debris in soil, they gain access to territory or resources previously held by the pathogen (Boddy 2000; Holmer and Stenlid 1993; Jensen et al. 2016). Many fungi are able to outcompete $F$. graminearum and are studied for their ability to limit the survival of the pathogen. Of these, Trichoderma atroviride, T. harzianum, and Clonostachys rosea, as well as Microsphaeropsis, are good candidates due to their ability to colonize wheat residues or to reduce $F$. graminearum sporulation on cultural debris (Bujold et al. 2001; Gromadzka et al. 2012; Naef et al. 2006; Sarrocco and Vannacci 2018). T. gamsii T6085 has been used in both laboratory and field experiments for the control of FHB causal agents, and has reduced $F$. graminearum and $F$. culmorum growth by acting as an antagonist and a mycoparasite (Baroncelli et al. 2016; Matarese et al. 2012; Sarrocco et al. 2013). In plate tests, on boiled rice, the activity of $T$. gamsii $\mathrm{T} 6085$ also resulted in a significant reduction in deoxynivalenol (DON) production by the pathogens after 21 days, thus showing the potential to reduce the risk of accumulation of this mycotoxin (Matarese at al. 2012). However, not much is known about the competitive ability of T. gamsii T6085, although Trichoderma spp. are among the main competitors that aggressively colonize the crop residues of maize and wheat throughout the decomposition process (Broder and Wagner 1988). Among the competitive species for cultural debris, F. oxysporum is an effective colonizer of partially decomposed wheat residues, and has a greater saprophytic ability than common FHB causal agents (Pereyra et al. 2004). From a large collection of F. oxysporum isolates recovered from wheat soils by straw baits, the isolate $F$. oxysporum 7121 used in the present work is also 
considered particularly interesting due to its ability to grow in the presence of DON (Sarrocco et al. 2012).

In this work, T. gamsii T6085 was used, for the first time, in combination with $F$. oxysporum 7121 against $F$. graminearum. We used a metabolic approach to investigate whether exploitation competition could explain the antagonistic activity performed by the two beneficial isolates against the pathogen on natural substrates. As far as we know, this is the first time that an ecological study has been performed to explain the kind of competition that could be involved in a multitrophic biocontrol of FHB.

\section{MATERIALS AND METHODS}

Fungal isolates. T. gamsii T6085 was isolated in Crimea (Ukraine) from uncultivated soil (Matarese et al. 2012). F. oxysporum 7121 belongs to a wider collection of $F$. oxysporum strains isolated from wheat straw in soils close to Pisa (Italy) with a previous history of wheat cultivation. This isolate was selected because it is able to grow in presence of DON at $50 \mathrm{ppm}$ (Sarrocco et al. 2012). Both beneficial isolates are deposited in the Fungal Collection of the Plant Pathology \& Mycology Lab (Dipartimento di Scienze Agrarie, Alimentari e Agro-Ambientali, University of Pisa).

F. graminearum ITEM 124, isolated from rice, belongs to the fungal collection of the CNR-ISPA (http://www.ispa.cnr.it/Collection; Bari, Italy), and its genome was recently sequenced, annotated, and released (Zapparata et al. 2017). All fungi were maintained on potato dextrose agar (PDA) $(\mathrm{BD}, \mathrm{Difco})$ under mineral oil at $4^{\circ} \mathrm{C}$ for long-term storage and grown on PDA (T. gamsii and $F$. oxysporum) or oat meal agar $(\mathrm{OA})(\mathrm{BD}, \mathrm{Difco})(F$. graminearum $)$ at $24^{\circ} \mathrm{C}$, under a photoperiod of $12 \mathrm{~h}$ of light and $12 \mathrm{~h}$ of darkness, when actively growing cultures were needed. The pathogen has been regularly passaged through the host plant to maintain its virulence.

Competition test on natural substrates. In order to estimate the effects of T. gamsii T6085 and F. oxysporum 7121 on $F$. graminearum growth and trichothecene production, a competition test was performed on two natural substrates, rice and wheat. In all, $20 \mathrm{~g}$ of rice or wheat kernels and $8 \mathrm{ml}$ of distilled water were put in a $100-\mathrm{ml}$ Erlenmeyer flask and autoclaved twice, at 24-h intervals, for $30 \mathrm{~min}$ at $121^{\circ} \mathrm{C}$. Kernels were inoculated with $1 \mathrm{ml}$ of a suspension of $2.0 \times 10^{6}$ conidia $\mathrm{ml}^{-1}$ of water made from 2-week-old PDA ( $T$. gamsii T6085 and $F$. oxysporum 7121 ) or OA ( $F$. graminearum) fungal cultures, grown at $24^{\circ} \mathrm{C}$, under a photoperiod of $12 \mathrm{~h}$ of light and $12 \mathrm{~h}$ of darkness. The pathogen was inoculated alone (FG) as a biotic control and coinoculated with each antagonist (FG+T or FG+ $\mathrm{FO})$ or in the presence of both $(\mathrm{FG}+\mathrm{T}+\mathrm{FO})$. Uninoculated rice and wheat were used as abiotic controls. Flasks were incubated at $24^{\circ} \mathrm{C}$ under $12 \mathrm{~h}$ of light and $12 \mathrm{~h}$ of darkness for 21 days. The experiment was independently repeated three times.

At the end of the incubation time, the growth of T. gamsii T6085 and $F$. oxysporum 7121 and their effects, alone and in combination, on the growth of $F$. graminearum and mycotoxin production were evaluated as described below. Values of both fungal growth and mycotoxin production were submitted to analysis of variance (Tukey post hoc test) using Systat (Systat Software, Inc.) and assuming $P \leq 0.05$ as the significance level.

Fungal growth. The growth of T. gamsii T6085, F. oxysporum 7121 , and $F$. graminearum on natural substrates was expressed as the DNA concentration of the two antagonists and of the pathogen, and measured by real-time polymerase chain reaction (PCR) (absolute and relative). Genomic DNA from inoculated seed was extracted according to Doyle and Doyle (1990), with some modifications. Briefly, $0.5 \mathrm{~g}$ of inoculated and control wheat and rice seed were used. Seed were ground in liquid nitrogen and homogenized in a cetyltrimethylammonium bromide (CTAB) extraction buffer consisting of $1.4 \mathrm{M} \mathrm{NaCl}, 20 \mathrm{mM}$ EDTA, $100 \mathrm{mM}$ Tris- $\mathrm{HCl}$ (pH 8.0), 3\% (wt/vol) CTAB, and $0.2 \%$ (vol/vol) 2-mercaptoetanol in a 6:1 ratio ( $\mathrm{vol} / \mathrm{wt})$. The mixture was incubated for $20 \mathrm{~min}$ at $60^{\circ} \mathrm{C}$, then extracted twice with chloroform-isoamyl alcohol (24:1). The upper phase was recovered, 2:3 volumes (vol/ vol) of cold isopropyl alcohol were added, and DNA was precipitated at $-20^{\circ} \mathrm{C}$ for $1 \mathrm{~h}$. The pellet obtained after centrifugation was washed with absolute ethanol and dissolved in TrisEDTA, pH 7.8 (10 mM Tris- $\mathrm{HCl}[\mathrm{pH} 7.8]$ and $1 \mathrm{mM}$ EDTA). Solubilized DNA was treated with RNaseA from bovine pancreas (Sigma) at a final concentration of $1 \mu \mathrm{g} \mathrm{ml}{ }^{-1}$, incubated at $37^{\circ} \mathrm{C}$ for 1 $\mathrm{h}$, and extracted with an equal volume of chloroform-isoamyl alcohol (24:1). The aqueous layer was recovered and 0.1 volume ( $\mathrm{vol} / \mathrm{vol}$ ) of $3 \mathrm{M}$ sodium acetate ( $\mathrm{pH}$ 6.6) and 2 volumes of ice-cold ethanol were added. DNA was precipitated at $-20^{\circ} \mathrm{C}$ for $1 \mathrm{~h}$. The pellet obtained after centrifugation was washed with $70 \%$ ethanol, dissolved in sterile water, and stored at $-80^{\circ} \mathrm{C}$. As a positive control, the DNA of all isolates was extracted from $100 \mathrm{mg}$ of mycelium collected from a PDA plate using a DNeasy Plant Mini Kit (Qiagen), following the manufacturer's instructions. All DNA samples were quantized using a Qubit dsDNA HS Assay Kit (Thermo Fisher), which is highly selective for double-stranded DNA (dsDNA) over RNA. DNA content was checked via $0.7 \%$ agarose gel electrophoresis.

For the absolute real-time PCR, the standard curve method was used in order to determine the absolute target quantity in samples according to Standard Curve Experiments (StepOne and StepOnePlus Real-Time PCR Systems PN 4376784F; Applied Biosystems). Measurements of fungal DNA in wheat and rice seed were taken by interpolation from a standard curve generated with a standard DNA, which was amplified in the same PCR run. The standard curve was generated from fivefold serial dilutions (ranging from $10 \mathrm{ng}$ to 0.1 pg per tube) of a known concentration of DNA and analyzed in triplicate in three independent assays. The amount of DNA was expressed as picograms per microliter. Quantitative reversetranscription (qRT)-PCR $(20 \mu \mathrm{l})$ was carried out with DNA from fungal pure mycelium or from seed samples, $250 \mathrm{nM}$ primers (FusGRAfw: 5' -TCTGCTCTTCCATCTCGTCGG-3'; FusGRArev: 5'-CGTGGCAGTAGTGACTGAACAAACC-3'; TGAMfw: 5' AACAACCTCCAAAAGTCCGCC-3'; TGAMrev1: 5'-CGGAA GAGCCGTTGTAGATACC-3'; FOXYfw: 5'-TCGATTTCCCC TACGACTCG-3'; FOXYrev: 5'-TCAAGTGGCGGGGTAAGTGC$3^{\prime}$ ), and $1 \times$ PowerUp SYBR Green Master Mix (Applied Biosystems) following the manufacturer's instructions. PCR was run in a StepOne real-time PCR System (Applied Biosystems) using the recommended thermal cycling conditions (hold at $95^{\circ} \mathrm{C}$ for $20 \mathrm{~s}$ and 40 cycles at $95^{\circ} \mathrm{C}$ for $3 \mathrm{~s}$ and $60^{\circ} \mathrm{C}$ for $30 \mathrm{~s}$ ). Primer specificity and the absence of primer-dimer formation during qRT-PCR analysis were indicated in each sample by the presence of a single peak in the dissociation (melt) curve at the end of the amplification program. Amplification efficiency, linearity, and working range were determined by linear regression analysis of serial dilutions of DNA.

Because an endogenous control gene could not be used due to the presence of both the substrate (seed) and fungal DNA in a variable ratio in each sample, a relative real-time PCR was performed to compare each sample with the cycle threshold $\left(\mathrm{C}_{\mathrm{t}}\right)$ obtained by amplifying the DNA extracted from seed treated only with each isolate, using the same primers previously described. qRT-PCR $(20 \mu \mathrm{l})$ were carried out with $10 \mathrm{ng}$ of DNA extracted from rice or wheat seed inoculated with $F$. graminearum and $F$. oxysporum or T. gamsii, $250 \mathrm{nM}$ primers, and 1× PowerUp SYBR Green Master Mix (Applied Biosystems) following the manufacturer's instructions. PCR was run in a StepOne Real-Time PCR System (Applied Biosystems) using the same recommended thermal cycling conditions described for the absolute real-time PCR. Amplifications of the target were run using three biological replicates, each with three technical replicates, and analyzed on the same plate in separate tubes. The relative abundance of amplicons was calculated by using the $2^{-\Delta \Delta C t}$ method (Livak and Schamittgen 2001).

Mycotoxin production. The effect of T. gamsii T6085 and F. oxysporum 7121 , alone and in combination, on mycotoxin production was evaluated and expressed as amount of trichothecenes 
DON, 3-acethyl DON (3ac-DON) and 15-acethyl DON (15ac-DON) produced by $F$. graminearum on rice and wheat. For the analysis of the trichothecenes, the sample preparation was performed as follows: $1 \mathrm{~g}$ of ground infected kernels was extracted with $10 \mathrm{ml}$ of acetonitrile/ water $(84: 16[\mathrm{vol} / \mathrm{vol}])$ on an orbital shaker for $2 \mathrm{~h}$. After filtration through filter paper (Whatman N.4), $6 \mathrm{ml}$ of the extract was passed through a Mycosep number 227 column (Romer Labs Diagnostic $\mathrm{GmbH}$ ) (Weingaertner et al. 1997). The purified extract (3 ml; equivalent to $0.3 \mathrm{~g}$ of sample) was dried under an air stream at $50^{\circ} \mathrm{C}$. The dried residue was reconstituted in $500 \mu \mathrm{l}$ of liquid chromatography (LC) mobile phase(i.e., water/methanol, 85:15 [vol/vol]). An ultrahigh-performance liquid chromatography (UPLC)-PDA analysis was performed according to Pascale et al. (2014). the UPLC (Waters) instrument was used with column Aquity UPLC BEH C18 ( 2.1 by $100 \mathrm{~mm}, 1.7 \mu \mathrm{m}$ ). The isocratic flow was set at $0.350 \mathrm{ml} \mathrm{min}^{-1}$ and the mobile phase was water/methanol $(85: 15[\mathrm{vol} / \mathrm{vol}])$. The injection volume was $10 \mu \mathrm{l}$ in a full-loop injection system. Toxins were detected in $220 \mathrm{~nm}$ with PDA spectra. The temperature of the column was set at $50^{\circ} \mathrm{C}$. Mycotoxin standards (purity $>99 \%$ ) were supplied by Sigma-Aldrich. Water was of Milli-Q quality (Millipore). All solvents (high-performance liquid chromatography grade) were purchased from J. T. Baker. Aliquots of the stock solution (100 $\mu \mathrm{g}$ $\mathrm{ml}^{-1}$ in acetonitrile) were evaporated to dryness under a stream of nitrogen at $50^{\circ} \mathrm{C}$. The residue was dissolved in the solvent and water/ methanol $(85: 15[\mathrm{vol} / \mathrm{vol}])$ was added for dilution. In the standard mix, the mycotoxin standard was used in concentrations of 0.1 and $10 \mu \mathrm{g} \mathrm{ml}^{-1}$. The detection limits of this method were $0.05 \mathrm{mg} \mathrm{kg}^{-1}$ for DON and $0.1 \mathrm{mg} \mathrm{kg}^{-1}$ for $3 \mathrm{ac}-\mathrm{DON}$ and $15 \mathrm{ac}-\mathrm{DON}$.

Metabolic analysis. In order to verify whether exploitation competition was the mechanism used to control $F$. graminearum growth on a natural substrate, metabolic requirements of $T$. gamsii T6085, F. oxysporum 7121 and F. graminearum were analyzed using the Biolog microarray system. In total, $100 \mu \mathrm{l}$ of a water spore suspension $\left(10^{6}\right.$ spore $\left.\mathrm{ll}^{-1}\right)$ of each of the three fungal isolates were inoculated in each well of a Biolog multiwell plate (filamentous fungi [FF] MicroPlate; Biolog; http://208.106.130.253/pdf/milit/ 00A\%20010rB\%20FF\%20Sell\%20Sheet\%20Mar07.pdf) containing water and 95 different carbon sources and incubated at $24^{\circ} \mathrm{C}$ for $12 \mathrm{~h}$ of light and $12 \mathrm{~h}$ of darkness. Three independent replicates were carried out for each strain. Fungal growth was spectrometrically measured every $4 \mathrm{~h}$ (12 h during the night) as absorbance (optical density [OD]) at $595 \mathrm{~nm}$ (Gardiner et al. 2009) for 11 days. OD values were used to calculate growth curves (GraphPad Software Inc.) and the slopes of the linear phase were used to create a heatmap showing a qualitative picture of the different metabolic abilities of each isolate. Hierarchical clustering of species and substrates according to slope values was performed and visualized using the heatmap package (Kolde 2015) in R (Chimalakonda et al. 2012).

For each isolate, slopes of the linear phase of growth curves on each of the 95 substrates were submitted to analysis of variance of regression to compare the slopes with the growth curve in water. The substrates whose slopes were significantly higher from those in water were considered to be metabolized $\left(P_{\text {slope }} \leq 0.05\right)$ and used to calculate the total number of carbon sources used by each isolate. For each substrate, the linear growth curves of two isolates (assumed as isolates $A$ and $B$ ) were submitted to analysis of variance of regression to compare their slopes. This detected which and how many substrates were used in the same way by the two isolates $\left(P_{\text {slope }} \geq 0.05\right)$.

These data were then used to calculate the niche overlapping index (NOI) between isolate A and isolate B, according to Wilson and Lindow (1994), with a small modification, as shown follows: $\mathrm{NOI}_{\mathrm{AB}}$ $=$ [number of carbon sources used in the same way $\left(P_{\text {slope }} \geq 0.05\right)$ by $\mathrm{A}$ and $\mathrm{B}] /\left[\right.$ total number of carbon sources used by A $\left(P_{\text {slope }} \leq 0.05\right.$ compared with water]. NOI was calculated for each combination of isolates $\mathrm{A}$ and $\mathrm{B}$, and expressed as $\mathrm{NOI}_{\mathrm{AB}}$ and $\mathrm{NOI}_{\mathrm{BA}}$.

Finally, all OD data were used to create growth curves for each isolate on each substrate. Each substrate was classified as slow (supporting a poor growth), medium (medium growth), and high (fast growth) by a semiparametric functional clustering method. The functional clustering was performed according to the following two steps implemented in the Functional Clustering Algorithms (Funcy) R package, version 0.8.6. (Yassouridis 2017), which was built to implement methods described by Chiou and $\mathrm{Li}$ (2007): (i) growth curves were estimated nonparametrically using spline basis functions, with coefficients chosen so as to include all time points in the estimation; and (ii) curve clustering was obtained by applying mixed-effect models to the base coefficients as implemented in the funcit function (method option 3; that is, iter Sub space, as described by Chiou and Li [2007]).

The procedure includes information on the entire curve and its behavior in the classification procedure.

Antibiosis and mycoparasitism. In order to preliminarily assess which mechanism could be involved in the interference competition between $F$. graminearum and the two beneficial isolates F. oxysporum 7121 and T. gamsii T6085, two antibiosis and one mycoparasitism test were performed.

Antibiosis in dual cultures. In the first experiment, PDA discs ( $6 \mathrm{~mm}$ in diameter), cut from the edge of actively growing colonies of each antagonist and of the pathogen, were placed at opposite sides $(4.5 \mathrm{~cm}$ from each other) on PDA plates. Plates were incubated at $24^{\circ} \mathrm{C}$, under a photoperiod of $12 \mathrm{~h}$ of light and $12 \mathrm{~h}$ of darkness. The radius of each fungal colony, both facing the colony of the other isolate and in a perpendicular (control) direction (Matarese et al. 2012), was measured three times a day, until contact. Because the combination $T$. gamsii $\mathrm{T} 6085$ versus $F$. graminearum ITEM124 was already tested by Matarese et al. (2012), in the present work, the experiment was performed by inoculating $F$. oxysporum 7121 against F. graminearum and against $T$. gamsii $\mathrm{T} 6085$, this last to exclude a possible interaction between the two beneficial fungi. Each combination was set up in triplicate. Growth values were used to create curves further subjected to an analysis of variance of regression to compare the slope and the elevation of curves in the presence or absence of the other isolate, assuming $P<0.05$ as a significant level.

Evaluation of the effect of secondary metabolites. Antibiotic effect of secondary metabolites produced by the beneficial isolates was evaluated against $F$. graminearum. Potato dextrose broth (PDB) (BD Difco) spore suspensions of $F$. oxysporum 7121 (FO) and of T. gamsii T6085 (T) were inoculated, alone and in combination, in 250-ml Roux bottles containing $100 \mathrm{ml}$ of PDB at a final concentration of $10^{4}$ conidia $\mathrm{ml}^{-1}$. Uninoculated medium was used as a control. Each thesis consisted of three independent replicates. Bottles were incubated on a shaker at $100 \mathrm{rpm}$ and $24^{\circ} \mathrm{C}$ under a photoperiod of $12 \mathrm{~h}$ of light and $12 \mathrm{~h}$ of darkness for 21 days. At the end of the incubation period, culture broths were collected by filtering through a Miracloth layer and sterilized by filtration $(20 \mu \mathrm{m})$. Filtrates were used to evaluate $F$. graminearum growth in 96-well microplates ( $\mathrm{PbI}$ International) using a spectrophotometric approach. In detail, each well was filled with $150 \mu \mathrm{l}$ of filtered broth (from T. gamsii and F. oxysporum cultures, alone and in coculture) inoculated with $5 \mu \mathrm{l}$ of an aqueous spore suspension (at a final concentration of $10^{5}$ conidia $\mathrm{ml}^{-1}$ ) of $F$. graminearum prepared from OA cultures grown for 1 week at $24^{\circ} \mathrm{C}$ under a photoperiod of $12 \mathrm{~h}$ of light and $12 \mathrm{~h}$ of darkness. Three replicates (for each of the three independent replicated liquid cultures), with 6 wells each, were used. Fresh PDB inoculated with the pathogen was used as a control. Fungal growth was monitored for a period of $120 \mathrm{~h}$ by reading the absorbance of the suspensions at $595 \mathrm{~nm}(\mathrm{OD})$ every $4 \mathrm{~h}$ (or $12 \mathrm{~h}$ during the night) in a microplate reader 680 (Bio-Rad Laboratories). OD values were used to create growth curves. Data were subjected to analysis of variance of regression in order to compare the slope of the curve of the pathogen grown on PDB with those of the pathogen grown in the filtered media used to cultivate the antagonists, assuming $P<0.05$ as a significant level.

Mycoparasitism. PDA discs (6 $\mathrm{mm}$ in diameter), cut from the edge of an actively growing colony of each antagonist and pathogen, were placed at opposite sides $(4.5 \mathrm{~cm}$ from each other) 
on a sterile cellophane membrane (10 $\mathrm{cm}$ in diameter, food grade) laid on water agar (WA) medium (bacteriological agar at $20 \mathrm{~g}$ liter $^{-1}$ ) (BD Difco). Because the combination T. gamsii T6085 versus $F$. graminearum ITEM124 was already tested by Matarese et al. (2012), in the present work, the experiment was performed by inoculating $F$. oxysporum 7121 against $F$. graminearum and against
T. gamsii T6085, this last to exclude a possible interaction between the two beneficial fungi. Each fungal combination was set up in triplicate. Plates were incubated at $24^{\circ} \mathrm{C}$ under a photoperiod of $12 \mathrm{~h}$ of light and $12 \mathrm{~h}$ of darkness and, after 21 days, signs of mycoparasitism (coilings and short loops) between tested fungi were microscopically evaluated.
A

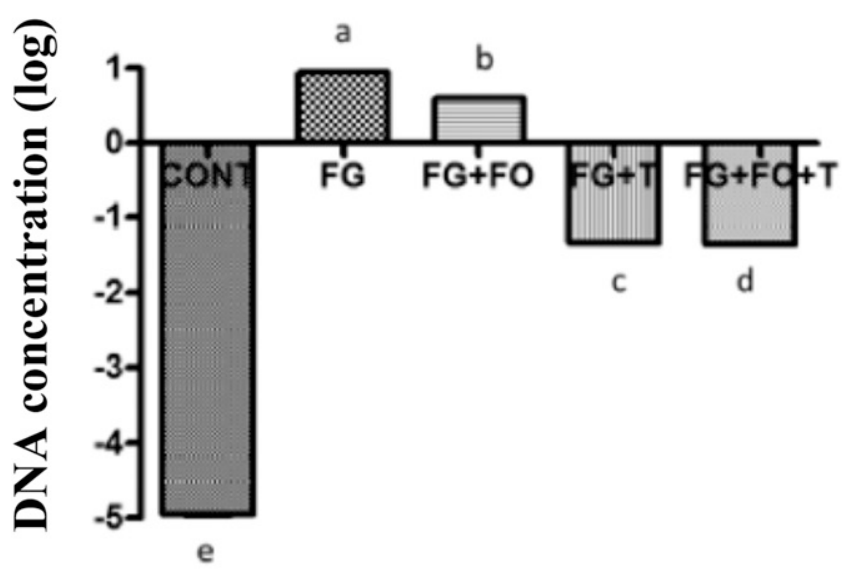

C

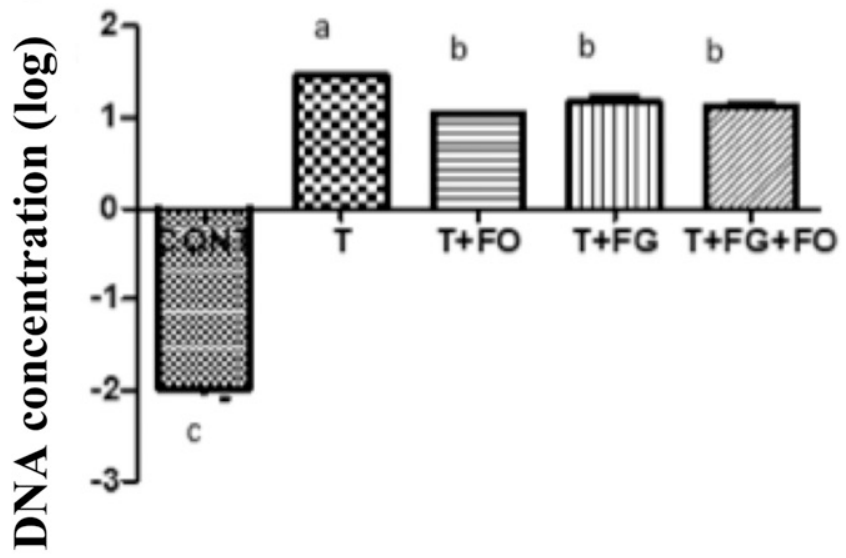

B

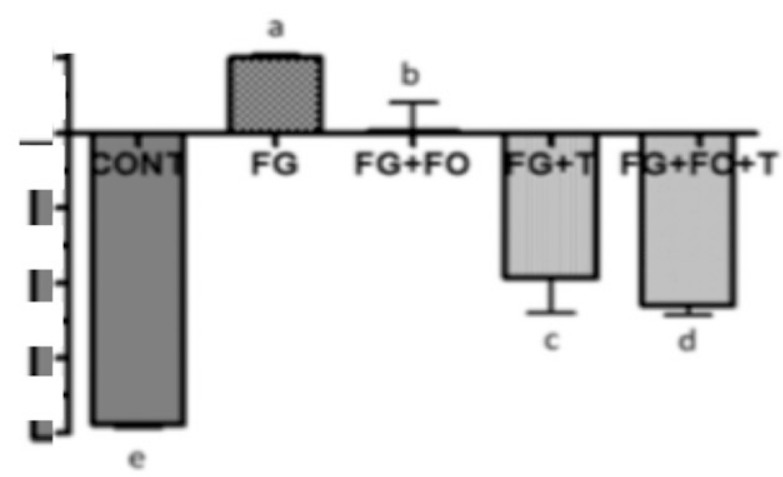

D

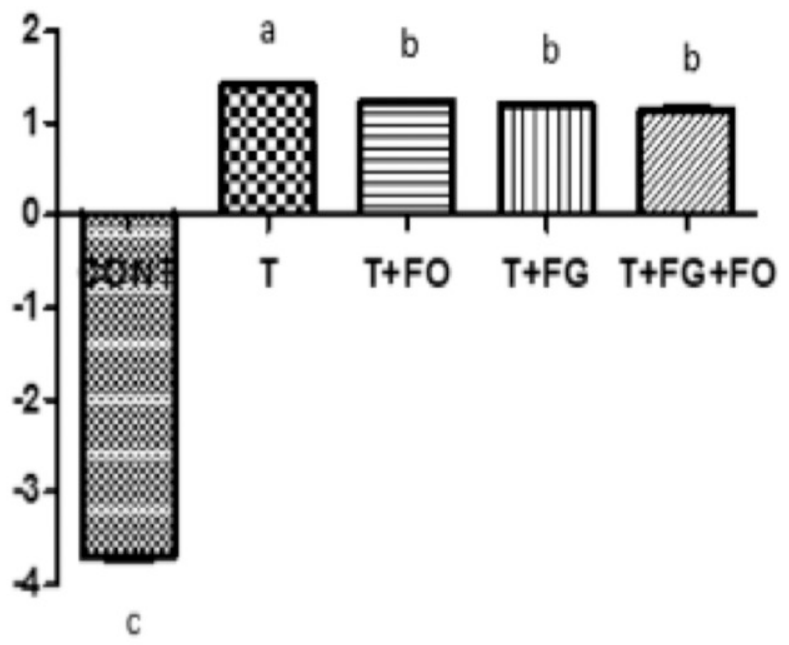

$\mathbf{F}$

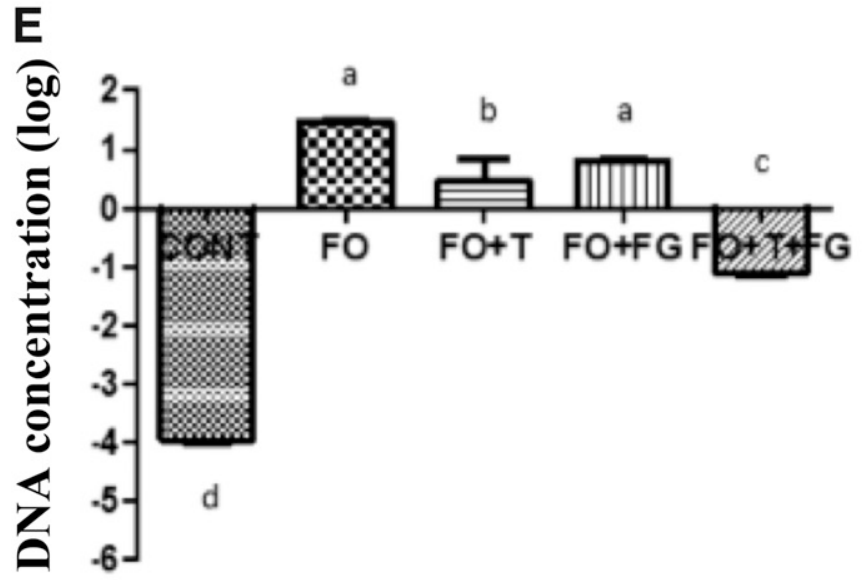

Samples

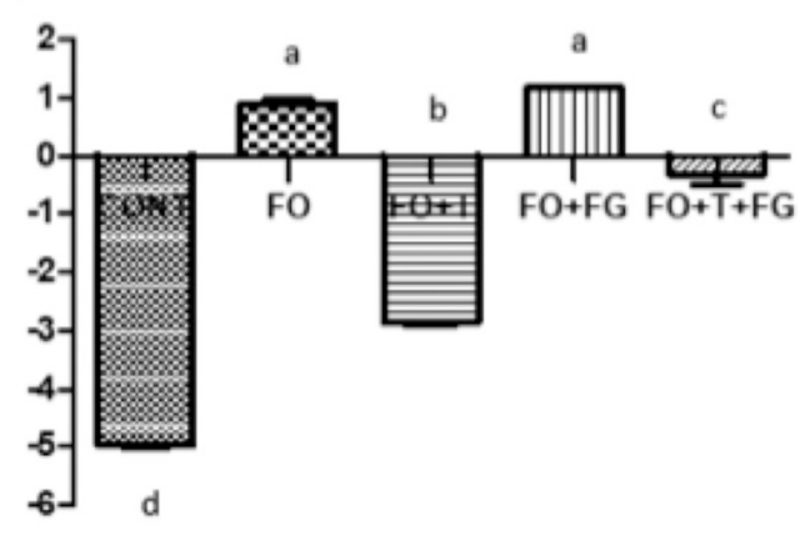

Samples

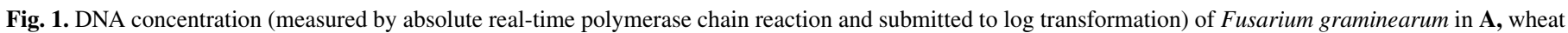
and B, rice kernels; Trichoderma gamsii T6085 in $\mathbf{C}$, wheat and $\mathbf{D}$, rice kernels; and F. oxysporum in $\mathbf{E}$, wheat and $\mathbf{F}$, rice kernels. CONT $=$ uninoculated kernels; $\mathrm{FG}=$ kernels inoculated with $F$. graminearum; $\mathrm{FG}+\mathrm{FO}=$ kernels inoculated with $F$. graminearum and $F$. oxysporum $7121 ; \mathrm{FG}+\mathrm{T}=$ kernels inoculated with $F$. graminearum and $T$. gamsii $\mathrm{T} 6085$; and $\mathrm{FG}+\mathrm{FO}+\mathrm{T}=$ kernels inoculated with $F$. graminearum, $T$. gamsii $\mathrm{T} 6085$, and $F$. oxysporum 7121 . Different letters within the same graph correspond to significantly different values (analysis of variance, $P \leq 0.05$ ). 


\section{RESULTS}

Competition test on natural substrates. A competition test was performed on both wheat and rice kernels in order to evaluate the growth of $T$. gamsii T6085 and F. oxysporum 7121 and their effects, alone and in combination, on the growth and mycotoxin production of $F$. graminearum after 21 days of incubation. Results obtained from the test and submitted to statistical analysis are shown here.

Fungal growth. Data obtained by absolute real-time PCR for all three fungi both on wheat and rice are shown in Figure 1. Because data obtained by relative real-time PCR analysis confirmed that obtained by absolute real-time PCR, they were not shown. No DNA contamination of $F$. graminearum, $T$. gamsii, and $F$. oxysporum was detected in uninoculated wheat and rice kernels.

When inoculated on wheat, the growth of $F$. graminearum was significantly reduced by the presence of $F$. oxysporum 7121 . With T. gamsii T6085, the pathogen's growth was even more strongly reduced, resulting in a significant difference when compared with the effect caused by $F$. oxysporum 7121 alone. However, when inoculated together, the two antagonists caused the highest significant growth inhibition of the pathogen (Fig. 1A). The same trend was observed on rice: growth of $F$. graminearum was significantly reduced by the two antagonists, both alone and coinoculated, with the highest significant effect obtained when T. gamsii T6085 and F. oxysporum 7121 were inoculated together (Fig. 1B).

When inoculated either on wheat or on rice, the growth of $T$. gamsii was significantly reduced by the presence of $F$. oxysporum and $F$. graminearum, both alone and coinoculated. However, no difference in $T$. gamsii growth was detected among these three latter samples $(\mathrm{T}+\mathrm{FO}, \mathrm{T}+\mathrm{FG}$, and $\mathrm{T}+\mathrm{FG}+\mathrm{FO})(\mathrm{Fig}$. $1 \mathrm{C}$ and $\mathrm{D})$. In any case, even if statistically significant, the reduction was not as evident as for F. graminearum.

When inoculated either on wheat or on rice, the growth of $F$. oxysporum was significantly reduced by $T$. gamsii, both alone and coinoculated with the pathogen, whereas no significant difference was detected with the pathogen alone (Fig. 1E and F).

Mycotoxin production. When inoculated on wheat, after 21 days of incubation, $F$. graminearum produced all three mycotoxins analyzed here, although in different amounts. The presence of F. oxysporum 7121 significantly reduced the amount of $15 \mathrm{Ac}-\mathrm{DON}$, whereas there was nonstatistically significant reduction of DON and 3Ac-DON. When in the presence of T. gamsii T6085, both alone and in combination with $F$. oxysporum 7121 , the production of all three mycotoxins was significantly reduced, with no different values compared with those detected in the uninoculated control (Table 1).

TABLE 1. Effects of Trichoderma gamsii T6085 and Fusarium oxysporum 7121 on mycotoxin production by $F$. graminearum on wheat

\begin{tabular}{lccc}
\hline & \multicolumn{3}{c}{ Mycotoxins $\left(\mu \mathrm{g} \mathrm{g}^{-1}\right)^{\mathrm{y}}$} \\
\cline { 2 - 4 } Samples $^{\mathrm{z}}$ & DON & 3Ac-DON & 15Ac-DON \\
\hline CONT & n.d. a & n.d. a & n.d. a \\
FG & $683.90 \mathrm{~b}$ & $20.23 \mathrm{~b}$ & $11.70 \mathrm{~b}$ \\
FG+FO & $278.10 \mathrm{ab}$ & $6.59 \mathrm{ab}$ & $6.77 \mathrm{a}$ \\
FG+T & $5.60 \mathrm{a}$ & n.d. a & n.d. a \\
FG+FO+T & $10.10 \mathrm{a}$ & n.d. a & n.d. a \\
\hline
\end{tabular}

y DON = deoxynivalenol, 3ac-DON = 3-acethyl DON, and 15ac-DON = 3acethyl DON. Different letters, within the same column, correspond to significantly different values (analysis of variance [ANOVA], $P \leq 0.05$ ). When mycotoxin contents were under the detection limits (n.d.), the detection limit values $\left(\mathrm{DON}=0.05 \mathrm{mg} \mathrm{kg}^{-1}\right.$ and $3 \mathrm{Ac}-\mathrm{DON}$ and $15 \mathrm{Ac}-\mathrm{DON}=$ $0.1 \mathrm{mg} \mathrm{kg}^{-1}$ ) were used to perform the ANOVA.

z No inoculation (CONT); F. graminearum (FG); F. graminearum and $F$. oxysporum 7121 (FG+FO); F. graminearum and T. gamsii T6085 (FG+T); and F. graminearum, F. oxysporum 7121, and T. gamsii $\mathrm{T} 6085$ (FG+FO+T).
When inoculated on rice, after 21 days of incubation, $F$. graminearum produced all three mycotoxins analyzed. When in presence of $F$. oxysporum 7121 , there was no statistically significant reduction of DON, 3Ac-DON, and 15Ac-DON. When in presence of $T$. gamsii $\mathrm{T} 6085$, both alone and in combination with $F$. oxysporum 7121 , the production of all three mycotoxins was lower, with a significant reduction for both DON and 3Ac-DON (Table 2).

Metabolic analysis. OD data were submitted to statistical analyses in order to define whether compounds included in the Biolog multiwall (FF) MicoPlates could be considered a potential source of competition. This test helped in analyzing whether exploitation competition could explain the effects of both the antagonists on the growth of the pathogen on wheat and rice kernels. Results of the hierarchical clustering analysis by a heatmap are shown in Figure 2. Many compounds are either not, or poorly, utilized by all fungi (for example, all of the compounds in cluster 2 , which includes the water control), while some compounds are better utilized by a single fungus (compounds in clusters 3 by $F$. graminearum, in cluster 4 by $T$. gamsii, and in cluster 5 by F. oxysporum). Almost all of the compounds included in cluster 1 are better utilized by the two Fusarium spp. (F. graminearum better than $F$. oxysporum) than by $T$. gamsii. Of note is the very high utilization rate of the compounds in cluster 1 from D-gluconic acid and L-malic acid by $F$. graminearum. This analysis suggests that the two antagonists are more related, from a metabolic point of view, to each other than to the $F$. graminearum isolate, the latter being able to use more substrates with higher slopes.

The compounds rapidly utilized by the various fungi do not overlap, apart from those from cluster 1, which are partially shared between the two Fusarium spp. The overlap in nutrient is better understood by the NOI. When slope values of the linear phase were used to calculate the NOI, according to the formula shown in Materials and Methods, all three isolates seem to occupy different niches, as shown in Table 3 ( $\mathrm{NOI}<0.9$ ).

Growth curves of the three isolates on 93 substrates (2 substrates-sebacic acid G2 and adenosine H10 - gave unclear results and were withdrawn from these analyses) calculated by the semiparametric "functional clustering" method, considering data collected during the whole experimental period, are shown in Figure 3. The substrates could be subdivided into three categories regarding their utilization: (i) high, (ii) medium, and (iii) slow (Fig. 3). F. graminearum mainly showed curves in the high group (Fig. 3B) whereas the curves referring to F. oxysporum 7121 and $T$. gamsii T6085 showed mainly substrates in the medium and slow groups (Fig. 3C and D, respectively).

For each category (slow, medium, and high) substrates are grouped according to the isolates (alone or in all the possible

TABLE 2. Effects of Trichoderma gamsii T6085 and Fusarium oxysporum 7121 on mycotoxin production by $F$. graminearum on rice

\begin{tabular}{lccc}
\hline & \multicolumn{3}{c}{ Mycotoxins $\left(\mu \mathrm{g} \mathrm{g}^{-1}\right)^{\mathrm{y}}$} \\
\cline { 2 - 4 } Samples $^{\mathrm{z}}$ & DON & 3Ac-DON & 15Ac-DON \\
\hline CONT & n.d. a & n.d. a & n.d. a \\
FG & $2814.70 \mathrm{~b}$ & $23.20 \mathrm{~b}$ & $134.35 \mathrm{a}$ \\
FG+FO & $1888.60 \mathrm{~b}$ & $16.78 \mathrm{ab}$ & $58.35 \mathrm{a}$ \\
FG+T & $90.60 \mathrm{a}$ & n.d. a & n.d. a \\
FG+FO+T & $95.20 \mathrm{a}$ & n.d. a & n.d. a \\
\hline
\end{tabular}

y DON = deoxynivalenol, 3ac-DON = 3-acethyl DON, and 15ac-DON = 3acethyl DON. Different letters, within the same column, correspond to significantly different values (analysis of variance [ANOVA], $P \leq 0.05$ ). When mycotoxin contents were under the detection limits (n.d.), the detection limit values $\left(\mathrm{DON}=0.05 \mathrm{mg} \mathrm{kg}^{-1}\right.$ and $3 \mathrm{Ac}-\mathrm{DON}$ and $15 \mathrm{Ac}-\mathrm{DON}=$ $0.1 \mathrm{mg} \mathrm{kg}^{-1}$ ) were used to perform ANOVA.

z No inoculation (CONT); F. graminearum (FG); F. graminearum and $F$. oxysporum 7121 (FG+FO); F. graminearum and T. gamsii T6085 (FG+T); and F. graminearum, F. oxysporum 7121, and T. gamsii T6085 (FG+FO+T). 
different combinations) that metabolize them (Table 4). Data presented in Table 4 and Figure 3 indicate that $F$. graminearum utilizes the carbon sources tested better than the other two fungi (17 slow, 22 medium, and 54 high), followed by F. oxysporum (31 slow, 62 medium, and 0 high) and then T. gamsii ( 70 slow, 23 medium, and
0 high). Within the slow category, 12 substrates are common to all three fungi. All, except four substrates, are in the same subcluster of cluster 2 along with water, as shown in the heatmap (Fig. 2), thus confirming that they are not metabolized by our fungi. There are more substrates in common between the two antagonists $(n=28)$

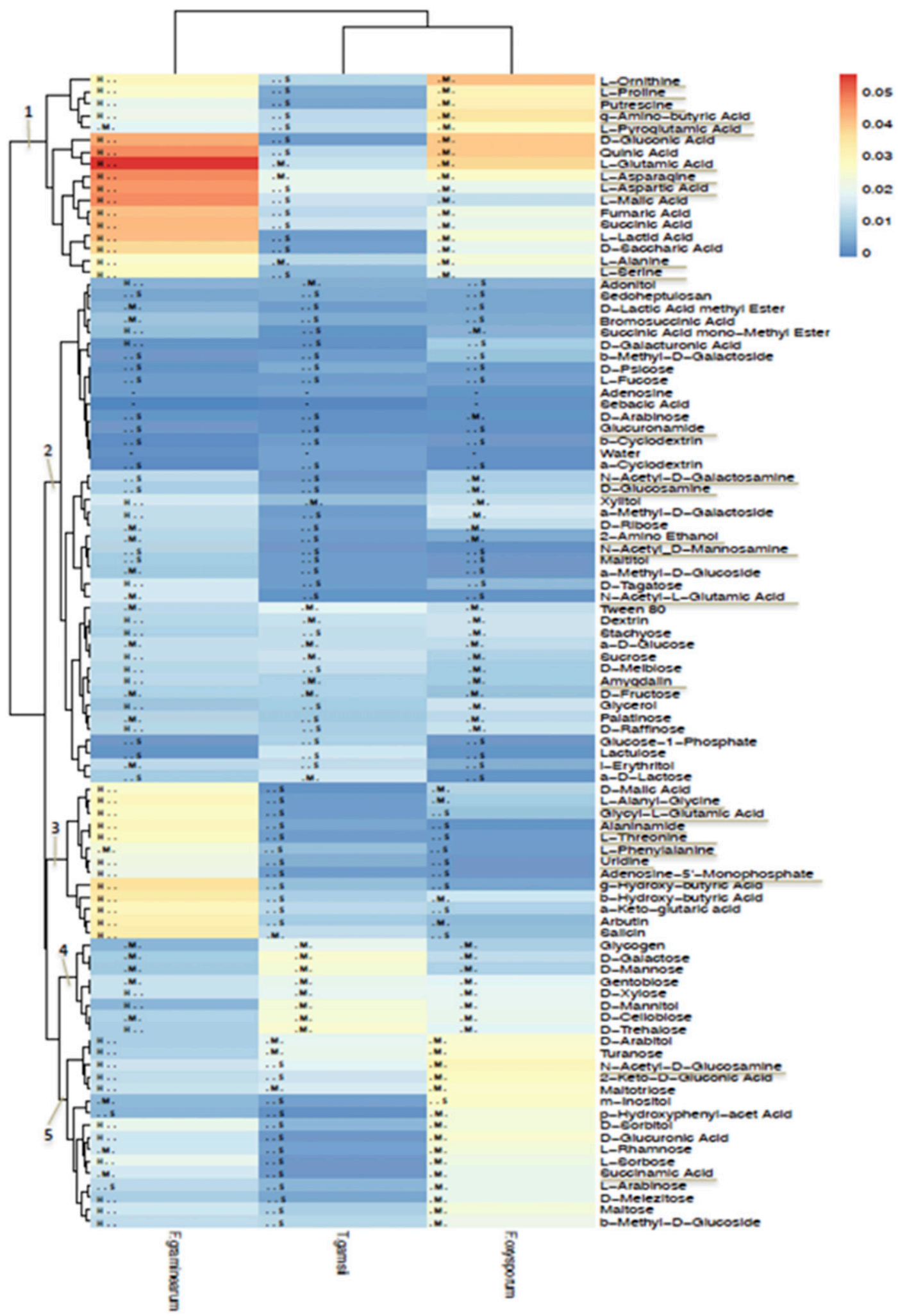

Fig. 2. Hierarchical clustering of isolates (Fusarium graminearum, F. oxysporum 7121, and Trichoderma gamsii T6085) and substrates (included into the Biolog Phenotype MicroArray filamentous fungi microplates) according to slope values of the linear phase of growth curves was performed and visualized using the heatmap package (Kolde 2015) within R (Chimalakonda et al. 2012). Slope values were calculated for each fungal growth curve for each substrate, using the optical density values measured by the Biolog system. Letters S, M, and $\mathrm{H}$ (slow, medium and high, respectively) within rectangles refer to the groups obtained by the semiparametric method. Some clusters are numbered (from 1 to 5) because they are commented on in the text. Underlined substrates contain nitrogen. 
TABLE 3. Niche overlapping index (NOI) of Fusarium graminearum, Trichoderma gamsii T6085, and $F$. oxysporum 7121 , according to the ability to grow on the 95 carbon source included in the Biolog filamentous fungi plates ${ }^{\mathrm{z}}$

\begin{tabular}{lccc}
\hline & \multicolumn{3}{c}{ Isolate B } \\
\cline { 2 - 4 } Isolate A & F. graminearum & T. gamsii T6085 & F. oxysporum 7121 \\
\hline F. graminearum & 1.00 & 0.17 & 0.13 \\
T. gamsii T6085 & 0.10 & 1.00 & 0.22 \\
F. oxysporum 7121 & 0.14 & 0.37 & 1.00 \\
\hline
\end{tabular}

${ }^{\mathrm{z}}$ NOI values are between 1 and 0 , and define whether or not fungi coexist. They occupy the same niche $\left(\mathrm{NOI}_{\mathrm{A} / \mathrm{B}}\right.$ and $\left.\mathrm{NOI}_{\mathrm{B} / \mathrm{A}}>0.9\right)$, they occupy separate niches $\left(\mathrm{NOI}_{\mathrm{A} / \mathrm{B}}\right.$ and $\left.\mathrm{NOI}_{\mathrm{B} / \mathrm{A}}<0.9\right)$, or one strain dominates $\left(\mathrm{NOI}_{\mathrm{A} / \mathrm{B}}>0.9\right.$ and $\mathrm{NOI}_{\mathrm{B} / \mathrm{A}}<0.9$ means isolate A nutritionally dominates over isolate $\left.\mathrm{B}\right)$.

Three isolates

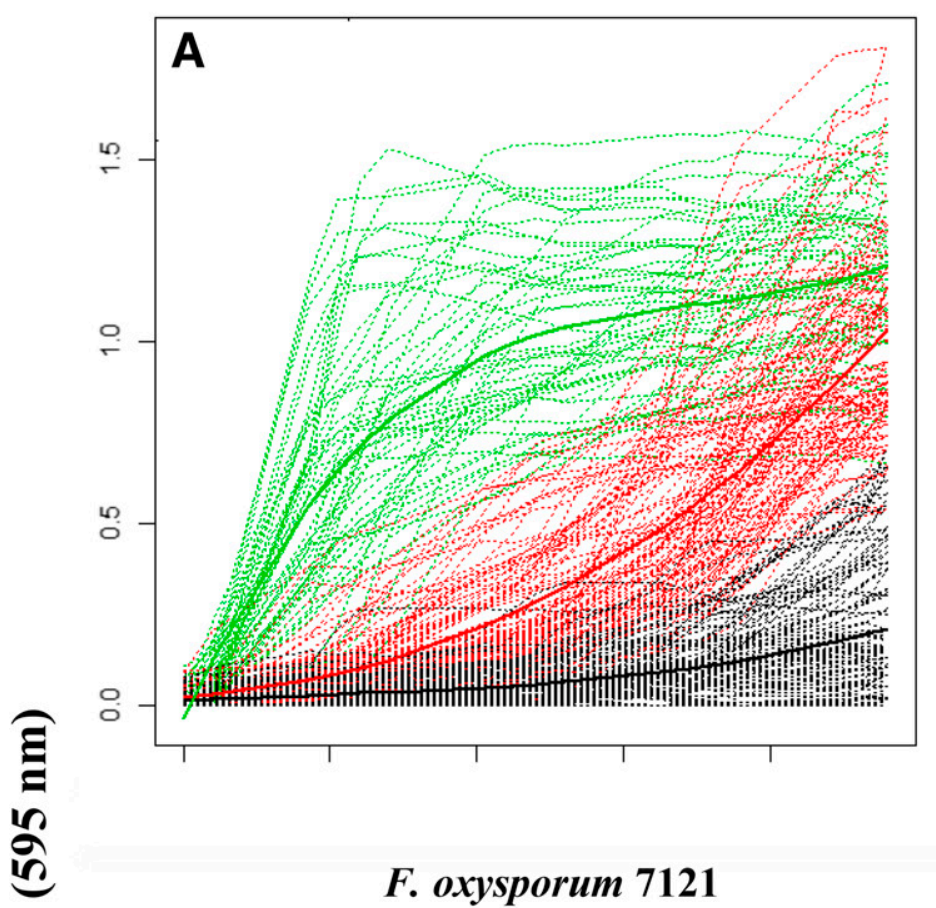

ชิ

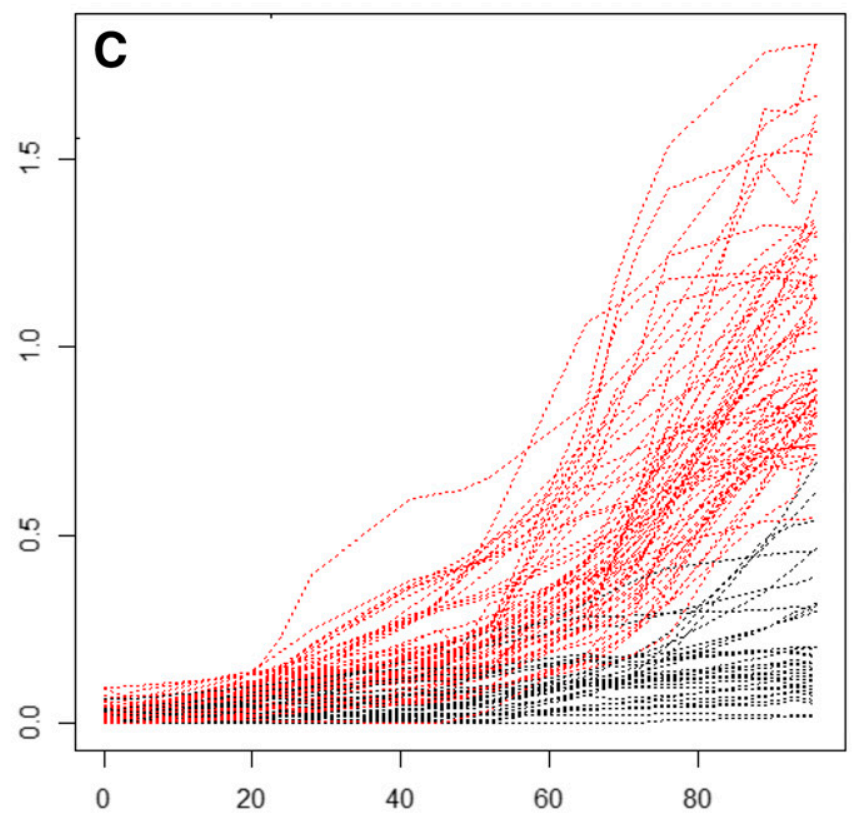

\section{F. graminearum}

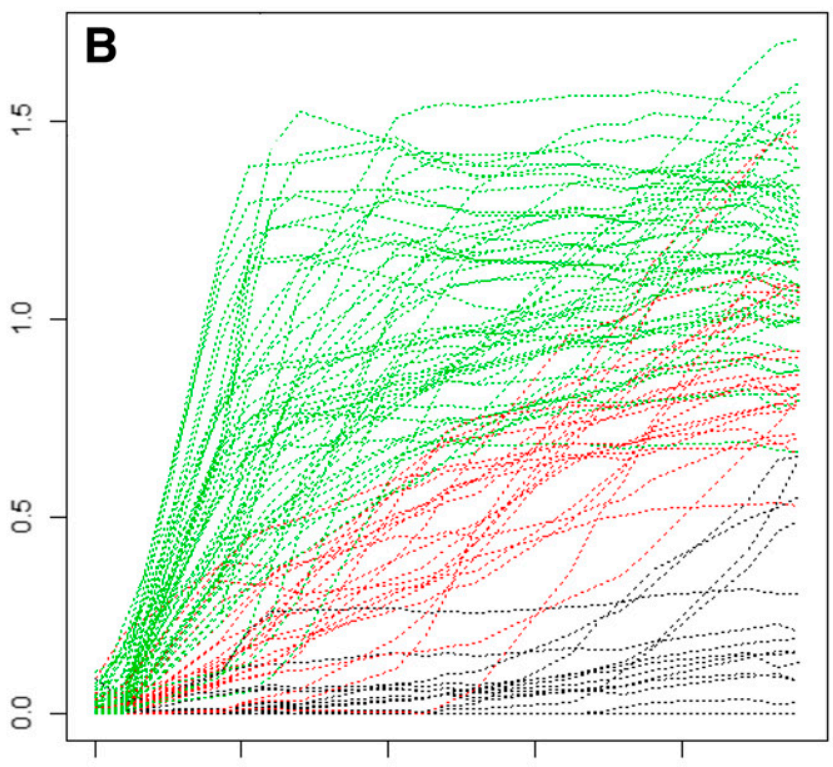

\section{T. gamsii T6085}

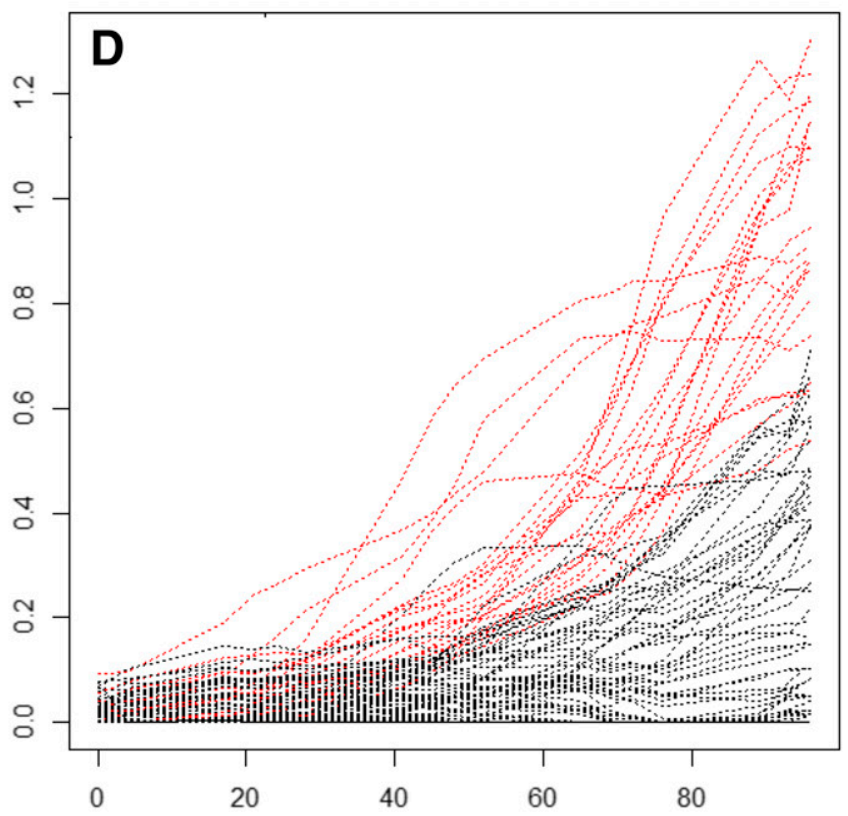

\section{Time (h)}

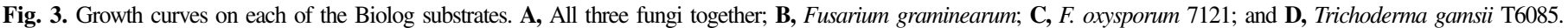

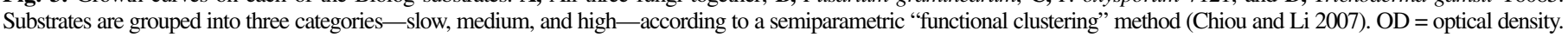


than between the pathogen and each of the two beneficial isolates $(n=11)$, in accordance with Table 4.

If the hierarchical clustering (heatmap) (Fig. 2) is compared with the functional clustering outputs (Fig. 3), a different picture appears, although always in favor of a better exploitation of substrates by $F$. graminearum. In total, 27 substrates coded in the white-blue range for the pathogen in the heatmap are now included in the high group. This suggests that the evaluation of the whole curve (richer in information if compared with the linear phase) gives us better information about the metabolization of substrates.

Antibiosis and mycoparasitism. In order to evaluate whether interference competition, by direct combat, could be the mechanism used by the two beneficial isolates, alone and in combination, against $F$. graminearum, antibiosis and mycoparasitism tests were performed. Results obtained by antibiosis tests and microscopic observations are reported. These results will be discussed together with those obtained in our earlier work (Matarese et al. 2012) (T. gamsii versus F. graminearum).

Antibiosis in dual cultures. F. oxysporum 7121 did not affect the growth of $F$. graminearum and T. gamsii T6085 in dual cultures on PDA. There were no significant differences in slope $(P=0.24)$ or elevation $(P=0.17)$ of growth curves of $F$. graminearum in presence or absence of $F$. oxysporum 7121 (Table 5). The same trend was observed for T. gamsii T6085 that showed no significant difference in slope $(P=0.89)$ or elevation $(P=0.66)$ of curves when in presence of the other beneficial isolate, compared with the control.

Evaluation of the effect of secondary metabolites. The effect of the cultural filtrates of $F$. oxysporum 7121 and T. gamsii T6085, alone and cocultured, on the growth of $F$. graminearum is shown in Table 6 . The growth of the pathogen was significantly reduced when inoculated in the cultural filtrates of T. gamsii T6085 alone or cocultured with $F$. oxysporum $7121\left(P_{\text {slope }}<0.0001\right.$ and $P_{\text {slope }}=$ 0.001 , respectively). Metabolites present in the cultural filtrate of $F$. oxysporum 7121 seem to affect only the elevation of $F$. graminearum growth curve, causing a delay in the beginning of the germination of its spore $\left(P_{\text {elevation }}=0.03\right)$ but without affecting the growth rate $\left(P_{\text {slope }}=0.090\right)$.

Mycoparasitism. We investigated whether $F$. oxysporum 7121 would coil or produce short loops on the hyphae of the pathogen, which are considered to be signs of mycoparasitism. F. oxysporum 7121 did not produce coils or short loops around the hyphae of the pathogen, thus excluding a direct mycoparasitic activity. When the zones of interaction between $F$. oxysporum 7121 and $T$. gamsii T6085 were microscopically observed, no signs of mycoparasitism between these two beneficial isolates were detected, thus excluding a detrimental interaction between them.

\section{DISCUSSION}

One of the most important parts of the life cycle of $F$. graminearum takes place outside the plant, where the pathogen produces a plethora of enzymes that allow it to use nutrient sources such as cultural debris both for its saprotrophic growth and for increasing the initial inoculum. In this environment, there is a strong competition not only against other Fusarium spp. belonging to the FHB species complex but also against other inhabitants with good saprotrophic fitness. To the best of our knowledge, this is the first study to use two or more beneficial fungi to control growth of $F$. graminearum and mycotoxin contamination. The present work evaluates, for the first time, the role of competition in a multitrophic approach involving a well-known beneficial isolate of T. gamsii and an F. oxysporum strain, the latter selected for its ability to colonize straw debris (Matarese et al. 2012; Sarrocco et al. 2012, 2013).

Because $F$. graminearum survival is enhanced by high quantities of available crop residues (Leplat et al. 2013), in the present work, we used two very nutrient rich substrates (i.e., wheat and rice kernels) on which $F$. graminearum grows very well and produces a high amount of DON (Matarese et al. 2012). In these conditions, its growth was significantly reduced by both the antagonists, with the copresence of $T$. gamsii and $F$. oxysporum as the most effective on both substrates. Under the same conditions, T. gamsii growth was

TABLE 4. Substrates included in the Biolog Phenotype MicroArray filamentous fungi microplates have been grouped into three categories—slow (S) medium (M), and high $(\mathrm{H})$ - according to a "functional clustering" semiparametric method and assigned to each fungus or group of fungi according to their ability to metabolize them

\begin{tabular}{|c|c|c|c|c|c|c|c|}
\hline \multirow[b]{2}{*}{ Category } & \multicolumn{7}{|c|}{ Substrates metabolized by ${ }^{z}$} \\
\hline & FG, T, FO & FG, FO & FG, T & $\mathrm{T}, \mathrm{FO}$ & FG & FO & $\mathrm{T}$ \\
\hline Slow (S) & $\begin{array}{l}\mathrm{A} 5, \mathrm{~B} 1, \mathrm{~B} 2, \\
\mathrm{~B} 6, \mathrm{~B} 8, \\
\mathrm{C} 1, \mathrm{C} 2, \\
\mathrm{C} 9, \mathrm{C} 10, \\
\text { D6, D10, E3 }\end{array}$ & $\mathrm{C} 8$ & $\begin{array}{l}\text { A3, A8, } \\
\text { A9, F6 }\end{array}$ & $\begin{array}{l}\text { B4, B11, C6, D7, } \\
\text { E8, F2, F5, F7, F8, } \\
\text { G6, G7, H1, H3, } \\
\text { H7, H11, H12 }\end{array}$ & $\cdots$ & A6, E2 & $\begin{array}{l}\text { A4, A11, B10, C3, C4, } \\
\text { C7, C11, D3, D4, D5, } \\
\text { D8, D9, D11, D12, } \\
\text { E1, E4, E5, E6, E11, } \\
\text { F1, F3, F4, F9, F10, } \\
\text { F11, F12, G1, G3, } \\
\text { G4, G5, G9, G11, H2, } \\
\text { H4, H5, H6, H8, H9 }\end{array}$ \\
\hline Medium (M) & $\begin{array}{l}\mathrm{A} 2, \mathrm{~A} 12, \\
\mathrm{~B} 5, \mathrm{~B} 7, \\
\mathrm{~B} 9, \mathrm{~B} 12, \\
\mathrm{C} 5, \mathrm{D} 2\end{array}$ & $\begin{array}{c}\text { D9, D12, } \\
\text { E1, G3, } \\
\text { H5, H8 }\end{array}$ & $\cdots$ & $\begin{array}{l}\text { A7, A10, B3, } \\
\text { C12, D1, } \\
\text { E7, E9, E10, E12, } \\
\text { G8, G10, G12 }\end{array}$ & $\begin{array}{c}\text { B4, B11, C6, D7, } \\
\text { F2, F8, G6, H3 }\end{array}$ & $\begin{array}{l}\text { A3, A4, A8, A9, A11, } \\
\text { B10, C3, C4, C7, } \\
\text { C11, D3, D4, D5, } \\
\text { D8, D11, E4, E5, } \\
\text { E6, E11, F1, F3, F4, } \\
\text { F6, F9, F10, F11, F12, } \\
\text { G1, G4, G5, G9, G11, } \\
\text { H2, H4, H6, H9 }\end{array}$ & $\mathrm{A} 6, \mathrm{C} 8, \mathrm{E} 2$ \\
\hline High $(\mathrm{H})$ & $\cdots$ & $\cdots$ & $\cdots$ & $\ldots$ & $\begin{array}{l}\text { A4, A6, A7, A10, A11, } \\
\text { B3, B10, C3, C4, C7, } \\
\text { C11, C12, D1, D3, D4, } \\
\text { D5, D8, D11, E2, E4, } \\
\text { E5, E6, E7, E8, E9, E10, } \\
\text { E11, E12, F1, F3, F4, F5, } \\
\text { F7, F9, F10, F11, F12, } \\
\text { G1, G4, G5, G7, G8, } \\
\text { G9, G10, G11, G12, } \\
\text { H1, H2, H4, H6, H7, } \\
\text { H9, H11, H12 }\end{array}$ & $\cdots$ & $\cdots$ \\
\hline
\end{tabular}

${ }_{\mathrm{z}} \mathrm{FG}=$ Fusarium graminearum, $\mathrm{T}=$ Trichoderma gamsii $\mathrm{T} 6085$, and $\mathrm{FO}=$ F. oxysporum 7121. 
slightly reduced in the presence of both the pathogen and F. oxysporum, either alone or coinoculated and on both substrates. This led us to hypothesize that the reduced growth of $T$. gamsii was related more to a lower availability of nutrients than to the presence of a given isolate. The behavior of $F$. oxysporum was slightly different because it was not affected by the presence of the pathogen alone but showed a growth reduction when co-occurring with $T$. gamsii, either alone or with $F$. graminearum, on both substrates. However, the strong positive effect of $F$. oxysporum against the pathogen, when coinoculated together with $T$. gamsii, suggests that the use of this mix would broaden its spectrum of applicability, while the possible additive or synergic effect of the two beneficial isolates needs to be better evaluated. Finally, on both substrates, the mycotoxin content was significantly reduced, thus demonstrating a double effect of the two competitive isolates on pathogen growth and mycotoxin production. This was reported also by Naef et al. (2006), who found a $36 \%$ reduction in DON production, when $F$. graminearum was inoculated in the presence of $T$. atroviride on autoclaved maize leaves. Recently, Tian et al. (2016) demonstrated the occurrence of modified mycotoxin deoxynivalenol-3-glucoside (D3G) - a well-known detoxification product of DON in plants - in the interaction of $F$. graminearum and Trichoderma spp. This provides evidence that Trichoderma isolates, able to reduce $F$. graminearum's growth, also possess a self-protection mechanism, as plants have, to detoxify DON into D3G when competing with this pathogen.

The two beneficial fungi seemed to have the capacity to outcompete the pathogen, at least in these semi-in-vivo conditions. Although artificial media are unrealistic and fail to reflect the complexity of the natural ecosystems, they offer a simpler model that enables those mechanisms to be extensively investigated, which are sometimes difficult to demonstrate in natural conditions (Crowther et al. 2018). Despite the need to consider additional environmental factors such as temperature, water, light, and $\mathrm{O}_{2}$ - key conditions for $F$. graminearum growth and the development of its sexual reproduction structures in nature-the system described here gives us a positive indication that the two antagonists have the potential to compete with the pathogen, thus reducing its development and mycotoxins production.

Exploitation competition can play a role in the control of pathogen growth and we used the Biolog Phenotype MicroArray, a high-throughput system for the identification of carbon sources and other nutrients used for the growth of various microorganisms that can be used to characterize the fungal metabolism, compare growth, and define nutritional utilization patterns (Druzhinina et al. 2006; Mohale et al. 2013). This information can be used to calculate the NOI in order to study how two or more organisms can compete for nutrients but excluding, at the same time, any direct interaction among the organisms.

We adopted two analyses, based on different assumptions: the "hierarchical clustering" method (according to slope values of the linear phase of curves), performed and visualized using the heatmap package (Kolde 2015) within R (Chimalakonda et al. 2012); and, for the first time, the semiparametric "functional clustering" method (Chiou and Li 2007), which takes into account the whole curve. Hierarchical clustering is a simplified method to compare fungal growth by comparing the slopes in the linear phase of growth curves. However, this adds uncertainty to the evaluation, because the linear phase is not so easy to define when 279 curves are taken into consideration. Moreover, the use of the linear phase slopes does not take into consideration the lag phase required by a fungus to adapt to a novel nutrient or the area under the curve, which represents the total amount of biomass produced by that fungus on that substrate. However, linear phase slopes better explain how the fungus grows and metabolizes single substrates over time compared with the more classical method that only takes into consideration the absorbance at one point in calculating the NOI (Mohale et al. 2013).

In addition to carbon sources, Biolog multiwell (FF) MicroPlates also contain 26 nitrogen sources, including 12 L-amino acids. In all, 17 of the 26 nitrogen-containing substrates (including 11 of the 12 L-amino acids tested) are in clusters 1 and 3 (and almost all in the high group) (Fig. 2), indicating that these substrates play an important role in competition. Among the nitrogen substrates in cluster 1 and in the high group, L-ornithine and the plant stress metabolite putrescine are both known to stimulate DON production (Gardiner et. al. 2009). DON could play an important role, which is not yet completely understood, during the interactions between the pathogen that produces it and one or more beneficial organisms. Therefore, in the multitrophic interactions that $F$. graminearum faces during its saprotrophic growth, the production of L-ornithine and putrescine is significant (Abid et al. 2011).

Our results confirm that $F$. graminearum can grow very fast, as reported also by Pereyra and Dill-Macky (2008). We also found no

TABLE 5. Antagonistic effect, expressed as fungal growth inhibition, of Fusarium oxysporum 7121 against $F$. graminearum and Trichoderma gamsii T6085 on a potato dextrose agar (PDA) plate ${ }^{\mathrm{z}}$

\begin{tabular}{|c|c|c|c|c|c|c|}
\hline Dual culture & & Slope $\left(\mathrm{mm} \mathrm{h}^{-1}\right)$ & $R^{2}$ & $P$ & $P_{\text {slope }}$ & $P_{\text {elevation }}$ \\
\hline \multirow[t]{2}{*}{ F. graminearum } & CONT & $0.39 \pm 0.01$ & 0.97 & $<0.0001$ & $\ldots$ & \\
\hline & vs $F$ oxysporum & $0.42 \pm 0.02$ & 0.97 & $<0.0001$ & 0.24 & 0.17 \\
\hline T. gamsii T6085 & CONT & $0.62 \pm 0.05$ & 0.92 & $<0.0001$ & $\ldots$ & \\
\hline
\end{tabular}

$\mathrm{z}$ Analysis of variance of regression of growth curves of $F$. graminearum and T. gamsii T6085 in dual culture with F. oxysporum 7121 on PDA. Slope $=$ fungal growth rate, $R^{2}$ and $P=$ significance of regression line, $P_{\text {slope }}=$ significance of differences between slopes of growth curves of the fungal isolate along the control radius (CONT) and along the radius facing $F$. oxysporum 7121, and $P_{\text {elevation }}=$ significance of differences between elevations of growth curves of the fungal isolate along the control radius (CONT) and along the radius facing F. oxysporum 7121.

TABLE 6. Antagonistic effect of cultural filtrates of Fusarium oxysporum 7121 and Trichoderma gamsii T6085 (alone and cocultured) on F. graminearum growth, expressed as optical density $(\mathrm{OD})^{\mathrm{z}}$

\begin{tabular}{|c|c|c|c|c|c|}
\hline Thesis & Slope & $R^{2}$ & $P$ & $P_{\text {slope }}$ & $P_{\text {elevation }}$ \\
\hline PDB & $0.009 \pm 0.000$ & 0.85 & $<0.0001$ & & \\
\hline PDB F. oxysporum 7121 & $0.009 \pm 0.000$ & 0.85 & $<0.0001$ & 0.090 & 0.003 \\
\hline PDB T. gamsii $\mathrm{T} 6085$ & $0.003 \pm 0.000$ & 0.70 & $<0.0001$ & $<0.0001$ & $\ldots$ \\
\hline
\end{tabular}

${ }^{\mathrm{z}}$ Analysis of variance of regression of growth curves of $F$. graminearum in potato dextrose broth (PDB) and in cultural filtrates of the two antagonists. Slope $=$ fungal growth rate expressed as OD, $R^{2}$ and $P=$ significance of regression line, $P_{\text {slope }}=$ significance of differences between slopes of growth curves of $F$. graminearum in PDB (control) and in PDB used to culture the two antagonists (alone and cocultured), and $P_{\text {elevation }}=$ significance of differences between elevations of the growth curves of $F$. graminearum in PDB (control) and in PDB used to culture the two antagonists (alone and cocultured). 
evident exploitation competition (direct competition for nutrients) among the pathogen and the two beneficial organisms, suggesting that interference competition could play a major role in the reduction of growth and mycotoxin production registered in the first experiment. Interference competition can be due to different mechanisms: physically, by direct hyphal contact (Rayner and Todd 1980), or with the involvement of soluble or volatile chemicals (Dix and Webster 1995). Secondary metabolites play a pivotal role in the antagonistic activities of some biocontrol species of Trichoderma, resulting in the suppression of fungal pathogens (Vinale et al. 2008, 2014). Our early interference competition study showed that T. gamsii T6085 significantly reduced the growth of $F$. graminearum on PDA and the antagonist produced coilings and short loops around the hyphae of the pathogen on WA (Matarese et al. 2012). In the present work, the same experiments were made in order to verify whether $F$. oxysporum 7121 also could reduce the growth of the pathogen and parasitize its mycelium. Our results showed neither growth inhibition nor signs of mycoparasitism of $F$. graminearum by $F$. oxysporum 7121 . F. oxysporum 7121 also showed no antagonistic or mycoparasitic activity against $T$. gamsii T6085. To verify whether the coculturing of the two antagonists could modify the effects recorded on PDA, cultural filtrates of T. gamsii T6085 and F. oxysporum 7121, alone and from coculture, were tested on spore germination and germling growth of $F$. graminearum. Our results showed that $T$. gamsii T6085 is able to produce, after 21 days of incubation in PDB - alone and cocultured with $F$. oxysporum 7121 - secondary metabolites that can significantly reduce the growth of the pathogen. F. oxysporum seems to be less effective in producing active secondary metabolites, because only a delay in the beginning of $F$. graminearum growth was registered.

Further investigations are required in order to move from the lab to the field the use of both these beneficial fungi in a multitrophic approach aimed at controlling FHB on wheat. However, a deeper knowledge of the ecological basis of FHB biocontrol by a multitrophic approach is a prerequisite to implement such a strategy as a wheat protection practice.

\section{ACKNOWLEDGMENTS}

We thank G. Jona Lanisio (Dipartimento di Scienze Statistiche, Università di Roma "La Sapienza", Italy) and A. Pollice (Dipartimento di Economia e Finanza, Università degli Studi di Bari “Aldo Moro", Italy) for the functional analysis clustering performed on the Biolog data.

\section{LITERATURE CITED}

Abid, M., Leplat, J., Fayolle, L., Gautheron, E., Héraud, C., Gautheron, N., Edel-Hermann, V., and Steinberg, C. 2011. Ecological role of mycotoxins in wheat crop residues: Consequences on the multitrophic interactions and the development of Fusarium graminearum. In: Working Group "Multitrophic Interactions in Soil", Cordoue, France. https://prodinra.inra.fr/?locale=en\#! ConsultNotice:50805

Baroncelli, R., Zapparata, A., Piaggeschi, G., Sarrocco, S., and Vannacci, G. 2016. Draft whole-genome sequence of Trichoderma gamsii T6085, a promising biocontrol agent of Fusarium head blight on wheat. Genome Announce. 4:e01747-15.

Boddy, L. 2000. Interspecific combative interactions between wood-decaying basidiomycetes. FEMS Microbiol. Ecol. 31:185-194.

Broder, M. W., and Wagner, G. H. 1988. Microbial colonization and decomposition of corn, wheat, and soybean residue. Soil Sci. Soc. Am. J. 52:112-117.

Bujold, I., Paulitz, T. C., and Carisse, O. 2001. Effect of Microsphaeropsis sp. on the production of perithecia and ascospores of Gibberella zeae. Plant Dis. 85:977-984.

Champeil, A., Dore, T., and Fourbet, J. F. 2004. Fusarium head blight: Epidemiological origin of the effects of cultural practices on head blight attacks and the production of mycotoxins by Fusarium in wheat grains. Plant Sci. 166:1389-1415.

Chimalakonda, K. R., Gudala, V., Gutta, M., Polisetty, M., and Koduri, S. V. S. 2012. Development and validation of chiral HPLC method for identification and quantification of (R) enantiomer in Ezetimibe. J. Am. J. Anal Chem. 3: Article 21044.
Chiou, J.-M., and Li, P.-L. 2007. L. Functional clustering and identifying substructures of longitudinal data. J. R. Stat. Soc. 69:679-699.

Crowther, T. W., Boddy, L., and Maynard, D. S. 2018. The use of artificial media in fungal ecology. Fungal Ecol. 32:87-91.

Dix, N. J., and Webster, J. 1995. Fungal Ecology. Chapman \& Hall, London.

Doyle, J. J., and Doyle, J. L. 1990. Isolation of plant DNA from fresh tissue. Focus 12:13-15.

Druzhinina, I. S., Schmoll, M., Seiboth, B., and Kubicek, C. P. 2006. Global carbon utilization profiles of wild-type, mutant, and transformant strains of Hypocrea jecorina. Appl. Environ. Microbiol. 72:2126-2133.

Fokkema, N. J. 1971. The effect of pollen in the phyllosphere of rye on colonization by saprophytic fungi and on infection by Helminthosporium sativum and other leaf pathogens [Het effect van stuifmeel in de fyllosfeer van rogge op de kolonisatie door saprofytische schimmels en op deinfectie door Helminthosporium sativum en andere bladpathogenen]. Neth. J. Plant Pathol. 77:1-60.

Gardiner, M. M., Landis, D. A., Gratton, C., DiFonzo, C. D., O’Neal, M. E., and Chacon, J. M. 2009. Landscape diversity enhances biological control of an introduced crop pest in the north-central USA. Ecol. Appl. 19: 143-154.

Gromadzka, K., Lenc, L., Sadowski, C. Z., Baturo-Cieśniewska, A., Chełkowski, J., and Goliński, P. 2012. Effects of fungicidal protection programs on the development of Fusarium head blight and the accumulation of mycotoxins in winter wheat. Cereal Res. Comm. 40:518-531.

Hartley, C. 1921. 1993. Damping-off in forest nurseries. US Dept Agric Bull 934:1-99.

Holmer, L., and Stenlid, J. 1993. The importance of inoculum size for the competitive ability of wood decomposing fungi. FEMS Microbiol. Ecol. 12: 169-176.

Jensen, D. F., Karlsson, M., and Lindahl, B. D. 2017. Fungal-fungal interactions: From natural ecosystems to managed plant production, with emphasis on biological control of plant diseases. In: The Fungal Community: Its Organization and Role in the Ecosystem, Fourth ed. J. Dighton and J. F. White, eds. CRC Press, Taylor and Francis Group.

Jensen, D. F., Karlsson, M., Sarrocco, S., and Vannacci, G. 2016. Biological control using microorganisms as an alternative to disease resistance. In: Biotechnology for Plant Disease Control. D. B. Collinge, eds. Wiley, New York and London.

Keddy, P. A. 2001. Competition, 2nd ed. Springer, New York.

Kinkel, L. L., Wilson, M., and Lindow, S. E. 1995. Effect of sampling scale on the assessment of epiphytic bacterial populations. Microb. Ecol. 29: 283-297.

Kolde, R. 2015. Pheatmap: Pretty Heatmaps. Online publication. R Package, Version 1.0.8. https://cran.r-project.org/web/packages/pheatmap/index.html

Leplat, J., Friberg, H., Abid, M., and Steinberg, C. 2013. Survival of Fusarium graminearum the causal agent of Fusarium head blight. A review. Agron. Sustain. Dev. 33:97-111.

Livak, K. J., and Schmittgen, T. D. 2001. Analysis of relative gene expression data using real-time quantitative PCR and the $2^{-\Delta \Delta C T}$ method. Methods 25: 402-408.

Matarese, F., Sarrocco, S., Gruber, S., Seidl-Seiboth, V., and Vannacci, G. 2012. Biocontrol of Fusarium head blight: Interactions between Trichoderma and mycotoxigenic Fusarium. Microbiol. 158:98-106.

Mohale, S., Medina, A., and Magan, N. 2013. Effect of environmental factors on in vitro and in situ interactions between atoxigenic and toxigenic A. flavus strains and control of aflatoxin contamination of maize. Biocontrol Sci. Technol. 23:776-793.

Naef, A., Senatore, M., and Défago, G. 2006. A microsatellite based method for quantification of fungi in decomposing plant material elucidates the role of Fusarium graminearum DON production in the saprophytic competition with Trichoderma atroviride in maize tissue microcosms. FEMS Microbiol. Ecol. 55:211-220.

Parry, D. W., Jenkinson, P., and McLeod, L. 1995. Fusarium ear blight (scab) in small grain cereals-A review. Plant Pathol. 44:207-238.

Pascale, M., Panzarini, G., Powers, S., and Visconti, A. 2014. Determination of deoxynivalenol and nivalenol in wheat by ultra-performance liquid chromatography/photodiode-array detector and immunoaffinity column cleanup. Food Anal. Methods 7:555-562.

Pereyra, S. A., and Dill-Macky, R. 2008. Colonization of the residues of diverse plant species by Gibberella zeae and their contribution to Fusarium head blight inoculum. Plant Dis. 92:800-807.

Pereyra, S. A., Dill-Macky, R. R., and Sims, A. L. 2004. Survival and inoculum production of Gibberella zeae in wheat residue. Plant Dis. 88: 724-730.

Pieters, M. N., Freijer, J., Baars, B. J., Fiolet Jacob, D. C. M., van Klaveren, J., and Slob, W. 2002. Risk assessment of deoxynivalenol in food: Concentration limits, exposure and effects. Pages 235-248 in: Mycotoxins and Food Safety. J. W. DeVries, M. W. Trucksess, and L. S.Jackson, eds. Kluwer Academic/Plenum Publishers, New York. 
Rayner, A. D. M., and Todd, N. K. 1980. Population and community structure and dynamics of fungi in decaying wood. Adv. Bot. Res. 7:333-420, 333A, 337420.

Sarrocco, S., Matarese, F., Moncini, L., Pachetti, G., Ritieni, A., Moretti, A. 2013. Biocontrol of Fusarium head blight by spike application of Trichoderma gamsii. J. Plant Pathol. S1:19-27.

Sarrocco, S., Matarese, F., Moretti, A., Haidukowski, M., and Vannacci, G. 2012. DON on wheat crop residues: Effects on mycobiota as a source of potential antagonists of Fusarium culmorum. Phytopathol. Mediterr. 51:225-235.

Sarrocco, S., and Vannacci, G. 2018. Preharvest application of beneficial fungi as a strategy to prevent postharvest mycotoxin contamination: A review. Crop Prot. 110:160-170.

Tian, Y., Tan, Y., Yan, Z., Liao, Y., Chen, J., de Saeger, S., Yang, H., Zhang, Q., and Wu, A. 2016. Detoxification of deoxynivalenol via glycosylation represents novel insights on antagonistic activities of Trichoderma when confronted with Fusarium graminearum. Toxins (Basel) 8:335.

Vinale, F., Sivasithamparam, K., Ghisalberti, E. L., Marra, R., Berbetti, M. J., Li, H., Woo, S. L., and Lorito, M. 2008. A novel role for Trichoderma secondary metabolites in the interactions with plants. Physiol. Mol. Plant Pathol. 72:80-86.
Vinale, F., Sivasithamparam, K., Ghisalberti, E. L., Woo, S. L., Nigro, M., Marra, R., Lombardi, N., Pascale, A., Ruocco, M., Lanzuise, S., Manganiello, G., and Lorito, M. 2014. Trichoderma secondary metabolites active on plants and fungal pathogens. Open Mycol. J. 8:127-139.

Weingaertner, J., Krska, R., Praznik, W., Grasserbauer, M., and Lew, H. 1997. Use of Mycosep multifunctional clean-up columns for the determination of trichothecenes in wheat by electron-capture gas chromatography. Fresenius J. Anal. Chem. 357:1206-1210.

Wilson, M., and Lindow, S. E. 1994. Ecological similarity and coexistence of epiphytic ice-nucleating (Ice $\left.{ }^{+}\right)$Pseudomonas syringae strains and a nonice-nucleating $\left(\mathrm{Ice}^{-}\right)$biological control agent. Appl. Environ. Microbiol. 60: 3128-3137.

Xu, X., and Nicholson, P. 2009. Community ecology of fungal pathogens causing wheat head blight. Annu. Rev. Phytopathol. 47:83-103.

Yassouridis, C. 2017. Funcy: Functional Clustering Algorithms. Online publication. R Package Version 0.8.6. https://rdrr.io/cran/funcy/

Zapparata, A., Da Lio, D., Somma, S., Vicente Muñoz, I., Malfatti, L., and Vannacci, G. 2017. Genome sequence of Fusarium graminearum ITEM 124 (ATCC 56091), a mycotoxigenic plant pathogen. Genome Announce. 5: e01209-17. 